\title{
Effects of floral neighborhood on seed set and degree of outbreeding in a high-alpine cushion plant
}

\author{
Lea R. Wirth • Nickolas M. Waser · René Graf · Felix Gugerli • Urs Landergott • \\ Andreas Erhardt · Hans Peter Linder · Rolf Holderegger
}

Received: 9 September 2010/Accepted: 22 March 2011/Published online: 12 April 2011

(C) Springer-Verlag 2011

\begin{abstract}
Plants flowering together may influence each other's pollination and fecundity over a range of physical distances. Their effects on one another can be competitive, neutral, or facilitative. We manipulated the floral neighborhood of the high-alpine cushion plant Eritrichium nanum in the Swiss Alps and measured the effects of coflowering neighbors on both the number of seeds produced and the degree of inbreeding and outbreeding in the offspring, as deduced from nuclear microsatellite markers. Seed set of E. nanum did not vary significantly with the presence or absence of two Saxifraga species growing as near neighbors, but it was higher in $E$. nanum cushions growing at low conspecific density than in those growing at high density. In addition, floral neighborhood had no detectable effect on the degree of selfing of E. nanum, but seeds from cushions growing at low conspecific density were more highly outbred than seeds from cushions at high density. Thus, there was no evidence of either competition
\end{abstract}

Communicated by Christina Caruso.

L. R. Wirth · R. Graf · F. Gugerli · U. Landergott

R. Holderegger $(\square)$

WSL Swiss Federal Research Institute,

Zürcherstrasse 111, 8903 Birmensdorf, Switzerland

e-mail: rolf.holderegger@wsl.ch

N. M. Waser

School of Natural Resources and the Environment, University of Arizona, Tucson, AZ 85721, USA

\footnotetext{
A. Erhardt

Integrative Biology, University of Basel,

St. Johanns-Vorstadt 10, 4056 Basel, Switzerland

H. P. Linder

Institute of Systematic Botany, University of Zurich,

Zollikerstrasse 107, 8008 Zurich, Switzerland
}

or facilitation between E. nanum and Saxifraga spp. as mediated by pollinators at the spatial scale of our experimental manipulation. In contrast, the greater fecundity of E. nanum cushions at low density was consistent with reduced intraspecific competition for pollinators and might also represent a beneficial effect of highly outbred seeds as brought about by more long-distance pollinator flights under low-density conditions.

Keywords Competition - Facilitation - Genetic paternity analysis · Inbreeding · Outbreeding · Realized mating · Scale effects

\section{Introduction}

Neighboring plants of the same or different species interact either positively or negatively by modifying each other's access to resources, including water, light, and nutrients. In addition, plants may interact over a wider range of physical distances through the activity of mobile animals, such as herbivores or pollinators. Insofar as the behavior of these animals changes with the properties of plant associations, individual plants can either increase or decrease components of the fitness of other plants growing within the range of distances moved by shared visitors.

Pollination provides both intuitive and non-intuitive examples of such effects (for reviews see Rathcke 1983; Waser 1983; Sargent and Ackerly 2008; Mitchell et al. 2009). The flowers of one plant may draw pollinators away from other plants, may leave the rate of pollinator visitation unchanged, or may enhance visitation for all plants involved. The first situation is likely to reduce the reproductive success of those plants receiving fewer visits, i.e, a competitive effect. Competition is even possible when 
per-capita visitation is unchanged because the pollen of one species may be lost on stigmas of other species or foreign pollen may compromise the ability of a flower to receive or use conspecific pollen (e.g., Morales and Traveset 2008; Mitchell et al. 2009). However, if the association with other plants enhances visitation rate, several final outcomes are possible. The deleterious effects of interspecific pollen transfer just described may overwhelm any benefit of greater visitation (Kunin 1993; Sargent and Ackerly 2008; Mitchell et al. 2009). The outcome may also be neutral, and, finally, it may be positive in the form of the facilitation of male or female reproductive success.

How can the type of interaction among plants be evaluated? An accurate assessment requires that we measure fitness or its components, rather than aspects of pollinator visitation alone, since even an enhanced rate of visitation may have either positive or negative effects on fitness. The easiest component of fitness to measure is fecundity through female sexual function (i.e., seed or fruit set), but fecundity through male function (seed siring) might also be affected. In addition to quantitative effects on the numbers of seeds set or sired, aspects of offspring quality might also respond to plant interactions. These aspects of quality include the degree of inbreeding or outbreeding of the seeds produced and the genotypic diversity of seed families (Campbell 1985; Bell et al. 2005), both of which can influence offspring viability and their eventual fecundity (Price and Waser 1979; Antonovics and Ellstrand 1984; Schmitt and Gamble 1990).

Plants growing under extreme conditions, for example at high elevations, may be especially likely to exhibit facilitation rather than competition in their use of water, light, and nutrients (Choler et al. 2001; Callaway et al. 2002; Kikvidze et al. 2005). High elevations might also foster facilitation among plants of the same or different species in the pollination of flowers. Insect flight at high elevations is restricted by periods of bad weather, and pollinator abundances may be low (Schröter 1926; Arroyo et al. 1982; Körner 2003) so that the number of insect visits received will often limit pollination and seed set. Because plant species often grow in discrete patches at high elevations (Kikvidze et al. 2005), larger aggregations of flowers might increase the number of pollinator visits to a patch by producing a larger visual or olfactory attraction signal. Of course, the final effect of pollinator attraction by co-flowering plants on components of their fitness also might be neutral or negative rather than facilitative, as described above.

Here we report on a manipulation of plant associations at high elevations in the Swiss Alps, where plants often grow as mats or cushions. We chose species that often grow in association and whose floral displays stand out against the surrounding rocks: Eritrichium nanum, with bright-blue flowers, and Saxifraga exarata ssp. exarata and $S$. bryoides, with white or yellowish flowers (Zoller et al. 2002). We created three contrasting floral neighborhood treatments that allowed us to investigate interactions within and between species mediated through pollinators. We assessed these interactions in terms of seed set and the genetic quality of the seed produced, i.e., their degree of inbreeding or outbreeding of seed families.

\section{Materials and methods}

Study species and sites

The perennial cushion plant Eritrichium nanum (L.) Gaud. (Boraginaceae) mainly grows at elevations between 2,500 and 3,000 $\mathrm{m}$ a.s.l. in the European Alps (Gams 1975), which corresponds to the sparsely vegetated alpine-subnival zone. During June and July, cushions produce many blue hermaphroditic flowers that offer nectar at the base of short floral tubes. The species is tetraploid (Wirth et al. 2009) and self-compatible (Wirth et al. 2010a). Its fruits carry up to four nutlets, each containing one seed (Wirth et al. 2010b). The subalpine to alpine cushion plants Saxifraga exarata ssp. exarata Vill. and S. bryoides L. (Saxifragaceae) often grow in association with E. nanum and flower at the same time, but the white or yellowish flowers of the latter species offer openly accessible nectar (Zoller et al. 2002), and their fruits contain many seeds (Kaplan 1995). The three species share pollinators, which are mostly insects of the order Diptera (Zoller et al. 2002).

During the summer of 2006, we performed a study in the Upper Engadine and adjacent valleys of southeastern Switzerland. We chose seven sites separated from one another by at least $1 \mathrm{~km}$. At each site we established a varying number of plots, as conditions allowed, in flat stabilized scree areas with naturally sparse vegetation. Overall, there were 60 plots situated at elevations between 2,750 and $3,055 \mathrm{~m}$ a.s.1. (Table 1). The plots at any given site were separated from one another by a minimum of $100 \mathrm{~m}$ of rocky outcrops, steep slopes, or rugged topography.

\section{Experimental treatments}

We established three different floral neighborhood treatments with 20 replicates each (Fig. 1): (1) three E. nanum cushions alone (low conspecific density for Eritrichium, hereafter En); (2) three E. nanum cushions with additional [mean \pm standard error $(\mathrm{SE})=8 \pm 1]$ E. nanum cushions (high conspecific density for Eritrichium, En + En); (3) three E. nanum cushions with Saxifraga neighbors (high interspecific density, $\mathrm{En}+\mathrm{S}$ ). All treatments were 
Table 1 Location and altitude of the study sites and numbers of plots per site used for experiments to evaluate seed set and genetic characteristics of seeds of E. nanum in southeastern Switzerland

\begin{tabular}{llllc}
\hline Study site & Longitude/latitude $(\mathrm{E} / \mathrm{N})$ & $\begin{array}{l}\text { Altitudinal } \\
\text { range }(\mathrm{m} \text { a.s.l. }\end{array}$ & \multicolumn{2}{c}{ Numbers of study plots } \\
\cline { 5 - 5 } & & Seed set & Genetics \\
\hline 1 & $9^{\circ} 43^{\prime} 00^{\prime \prime} / 46^{\circ} 31^{\prime} 42^{\prime \prime}$ & $2,945-2,995$ & 8 & 4 \\
2 & $9^{\circ} 35^{\prime} 18^{\prime \prime} / 46^{\circ} 27^{\prime} 74^{\prime \prime}$ & $2,760-2,850$ & 7 & 4 \\
3 & $9^{\circ} 36^{\prime} 75^{\prime \prime} / 46^{\circ} 25^{\prime} 61^{\prime \prime}$ & $2,750-2,795$ & 6 & 4 \\
4 & $9^{\circ} 43^{\prime} 88^{\prime \prime} / 46^{\circ} 30^{\prime} 00^{\prime \prime}$ & $2,800-2,910$ & 11 & 5 \\
5 & $9^{\circ} 57^{\prime} 00^{\prime \prime} / 46^{\circ} 31^{\prime} 77^{\prime \prime}$ & $2,895-2,900$ & 4 & 2 \\
6 & $9^{\circ} 59^{\prime} 32^{\prime \prime} / 46^{\circ} 28^{\prime} 64^{\prime \prime}$ & $2,815-3,020$ & 13 & 6 \\
7 & $9^{\circ} 46^{\prime} 80^{\prime \prime} / 46^{\circ} 30^{\prime} 42^{\prime \prime}$ & $2,820-3,055$ & 11 & 5 \\
Total & & & 60 & 30 \\
\hline
\end{tabular}

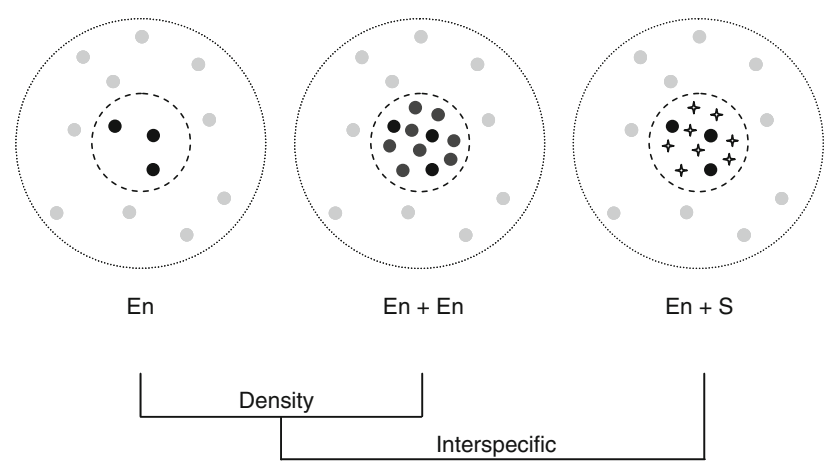

Fig. 1 Layout of floral neighborhood treatments. The inner dashed circles (radius $0.5 \mathrm{~m}$ ) contain one of three distinct treatments: low conspecific density for E. nanum (En), high conspecific density $(E n+E n)$, or high interspecific density for E. nanum and Saxifraga spp. $(E n+S)$. Black dots represent three focal E. nanum cushions, gray dots additional cushions within the inner circle, light-gray dots cushions within a ring of $1.5-\mathrm{m}$ radius (dotted) around the inner circle, stars Saxifraga spp. Square brackets indicate the treatments that will be compared to test interspecific and intraspecific density effects on performance

established within a circle of $0.5-\mathrm{m}$ radius in the center of a study plot, and the experimental treatments were maintained by repeatedly removing flowers from all other plants within this inner circle. We also trimmed flowers from the three focal cushions in each plot until we had produced similar floral displays of diameter $10-15 \mathrm{~cm}$. As pollinators also respond to overall floral density at larger spatial scales (Kunin 1993; Bosch and Waser 1999, 2001), we removed the flowers of all other plant species (including Saxifraga sp.) within an additional ring of radius $1.5 \mathrm{~m}$ around each central 0.5-m-radius circle and also removed flowers on any surplus $E$. nanum so as to achieve a total of ten E. nanum cushions in the 1.5-m-radius ring (Fig. 1).

\section{Seed number}

In July and August 2006, we counted all flowers, collected all fruits, and counted all expanded nutlets for the three focal E. nanum cushions in each plot, from which we calculated the mean number of seeds per flower.

\section{Genetic quality of offspring}

We used genetic analyses to explore treatment effects on aspects of offspring quality in E. nanum. We chose half of all plots in each treatment $(n=10$ per treatment), since a power analysis indicated that results would not change at $\alpha=5 \%$ when all plots were included. From each plot used, we collected leaves from the three focal cushions, from neighboring cushions in treatment En $+\mathrm{En}$, and from all other E. nanum cushions in the outer $1.5-\mathrm{m}$ ring and dried the leaves in silica gel. We randomly selected 13-23 nutlets from the focal cushions and excised their embryos. Genomic DNA of embryos and leaves from adult E. nanum was extracted with the DNeasy 96 Plant kit (QIAGEN, Hilden, Germany). Each sample was genotyped at six polymorphic, codominant nuclear microsatellite markers with tetrasomic inheritance, as described in Wirth et al. (2009). Matings of focal E. nanum cushions were then inferred from paternity analysis (Sork et al. 1999) using a full-exclusion approach to identify fathers (Chase et al. 1996). In a first step, we classified offspring carrying only maternal alleles as selfed. It should be noted that this approach may overestimate selfing insofar as matings between close relatives might produce nutlets also containing only maternal alleles. The remaining outcrossed offspring were then assigned as products of (1) "close" matings, i.e., matings among focal cushions within the inner circle of radius $0.5 \mathrm{~m}$; (2) "intermediate" matings, i.e., between focal cushions and cushions within the ring of radius $1.5 \mathrm{~m}$, and (3) "distant" matings, i.e., between focal cushions and unknown fathers outside the study plot (Fig. 1). For each of these three classes of matings, we then calculated the number of different alleles across all marker loci that were not shared with the maternal plant. This value indicates the degree of outbreeding of offspring (sensu Waser and Williams 2001). For tetrasomic inheritance and six loci, the maximum possible number of 
unshared alleles is 12 . In addition, we calculated the expected heterozygosities $\left(H_{\mathrm{e}}\right)$ and fixation indices $\left(F_{\mathrm{IS}}\right)$ of outcrossed offspring for each plot using AUTOTET (Thrall and Young 2000). $H_{\mathrm{e}}$ is the expected percentage of loci being in heterozygous state, calculated from observed allele frequencies under the assumption of random mating. $F_{\text {IS }}$ measures the proportional deviation of the observed heterozygosity in actual individuals from the expected heterozygosity and reflects deviations from random mating. $F_{\text {IS }}$ values significantly larger than zero are indicative of inbreeding.

\section{Statistical analyses}

We used general linear models in SPSS ver. 11.0 (SPSS, Chicago, IL) to test for an effect of the three neighborhood treatments (fixed factor) on (1) seed set and (2) selfing rate of focal $E$. nanum cushions, (3) $H_{\mathrm{e}}$ and (4) $F_{\text {IS }}$ of outcrossed $E$. nanum offspring, and (5) percentage of outcrossed offspring from close versus intermediate and distant matings. Models included study site as a random effect. In no case was the interaction between treatment and study site significant, so the interaction was dropped from the models. The treatment effect was further subdivided into planned orthogonal contrasts of (1) interspecific $(\mathrm{En}+\mathrm{S})$ versus conspecific (En and En + En) E. nanum neighborhoods and (2) low- versus high-density neighborhoods (En vs. En + En). We also used one-way analysis of variance (ANOVA) with planned orthogonal contrasts of (1) close versus intermediate and distant matings and (2) intermediate versus distant matings to examine whether the three mating distances influenced the percentage of unshared alleles. In no analysis did residuals from the models deviate from normality.

\section{Results}

Effects of floral neighborhood treatment on seed set

The mean seed set per flower of focal E. nanum cushions over all treatments was 0.69 . Treatment had a marginally significant overall effect $(P=0.056)$ on the seed set of focal $E$. nanum cushions (Table 2), mainly due to a reduction from an average of 0.75 seeds per flower in treatment En to an average of 0.57 in treatment En + En
Table 2 Results of general linear models and contrasts in testing the effects of treatments and location on seed set, selfing rate, expected heterozygosity $\left(H_{\mathrm{e}}\right)$, fixation index $\left(F_{\mathrm{IS}}\right)$, and percentage of outcrossed offspring from intermediate plus distant matings for focal E. nanum cushions
For contrasts, the contrast value and the lower and upper bounds of the $95 \%$ confidence interval (CI) are given (in parenthesis). Treatment: $\mathrm{En}=$ (low conspecific density for Eritrichium (three E. nanum cushions alone); En + En = high conspecific density for

Eritrichium (three E. nanum cushions with additional E. nanum cushions; $\mathrm{En}+\mathrm{S}=$ high interspecific density (three E. nanum cushions with Saxifraga neighbors)

\begin{tabular}{|c|c|c|}
\hline Parameters & Statistics & $P$ \\
\hline \multicolumn{3}{|l|}{ Seed set $E$. nanum } \\
\hline Treatment & $F_{2,51}=3.055$ & 0.056 \\
\hline Study site & $F_{6,51}=1.091$ & 0.380 \\
\hline En, En + En vs. En $+S$ & $0.076(-0.070,0.223)$ & 0.301 \\
\hline En vs. En + En & $-0.189(-0.358,-0.020)$ & 0.030 \\
\hline \multicolumn{3}{|c|}{ Percentage of selfed $E$. nanum offspring } \\
\hline Treatment & $F_{2,21}=1.162$ & 0.332 \\
\hline Study site & $F_{6,21}=0.525$ & 0.525 \\
\hline En, En + En vs. En $+S$ & $11.538(-6.056,29.132)$ & 0.187 \\
\hline En vs. En + En & $-6.729(-27.524,14.067)$ & 0.508 \\
\hline \multicolumn{3}{|c|}{$H_{\mathrm{e}}$ of outcrossed $E$. nanum offspring } \\
\hline Treatment & $F_{2,21}=0.053$ & 0.949 \\
\hline Study site & $F_{6,21}=1.302$ & 0.299 \\
\hline En, En + En vs.En $+S$ & $-0.002(-0.044,0.048)$ & 0.932 \\
\hline En vs. En + En & $0.011(-0.013,0.038)$ & 0.405 \\
\hline \multicolumn{3}{|c|}{$F_{\text {IS }}$ of outcrossed $E$. nanum offspring } \\
\hline Treatment & $F_{2,21}=0.299$ & 0.745 \\
\hline Study site & $F_{6,21}=1.487$ & 0.231 \\
\hline En, En + En vs. En $+S$ & $-0.011(-0.059,0.082)$ & 0.718 \\
\hline En vs. En + En & $-0.002(-0.034,0.037)$ & 0.930 \\
\hline \multicolumn{3}{|c|}{ Percentage of outcrossed E. nanum offspring from intermediate plus distant matings } \\
\hline Treatment & $F_{2,21}=2.718$ & 0.089 \\
\hline Study site & $F_{6,21}=1.611$ & 0.194 \\
\hline En, En + En vs. En $+S$ & $-3.487(-17.177,10.203)$ & 0.602 \\
\hline En vs. En + En & $-17.693(-33.874,-1.511)$ & 0.034 \\
\hline
\end{tabular}


Fig. 2 Effects of floral neighborhood on seed set of focal E. nanum (a), percentage of selfed offspring of focal $E$. nanum $(\mathbf{b})$, heterozygosity $\left(H_{\mathrm{e}}\right)$ $(\mathbf{c})$ and fixation index $\left(F_{\text {IS }}\right)(\mathbf{d})$ of outcrossed $E$. nanum offspring, and percentage of outcrossed offspring from intermediate and distant matings (e, i.e., those $>0.5 \mathrm{~m}$ ). Values are given as means (open circles) \pm standard errors (SE) (whiskers). For the contrasts (square brackets) shown below each $x$-axis, asterisks indicate means that are significantly different $(P<0.05)$, ns not significant
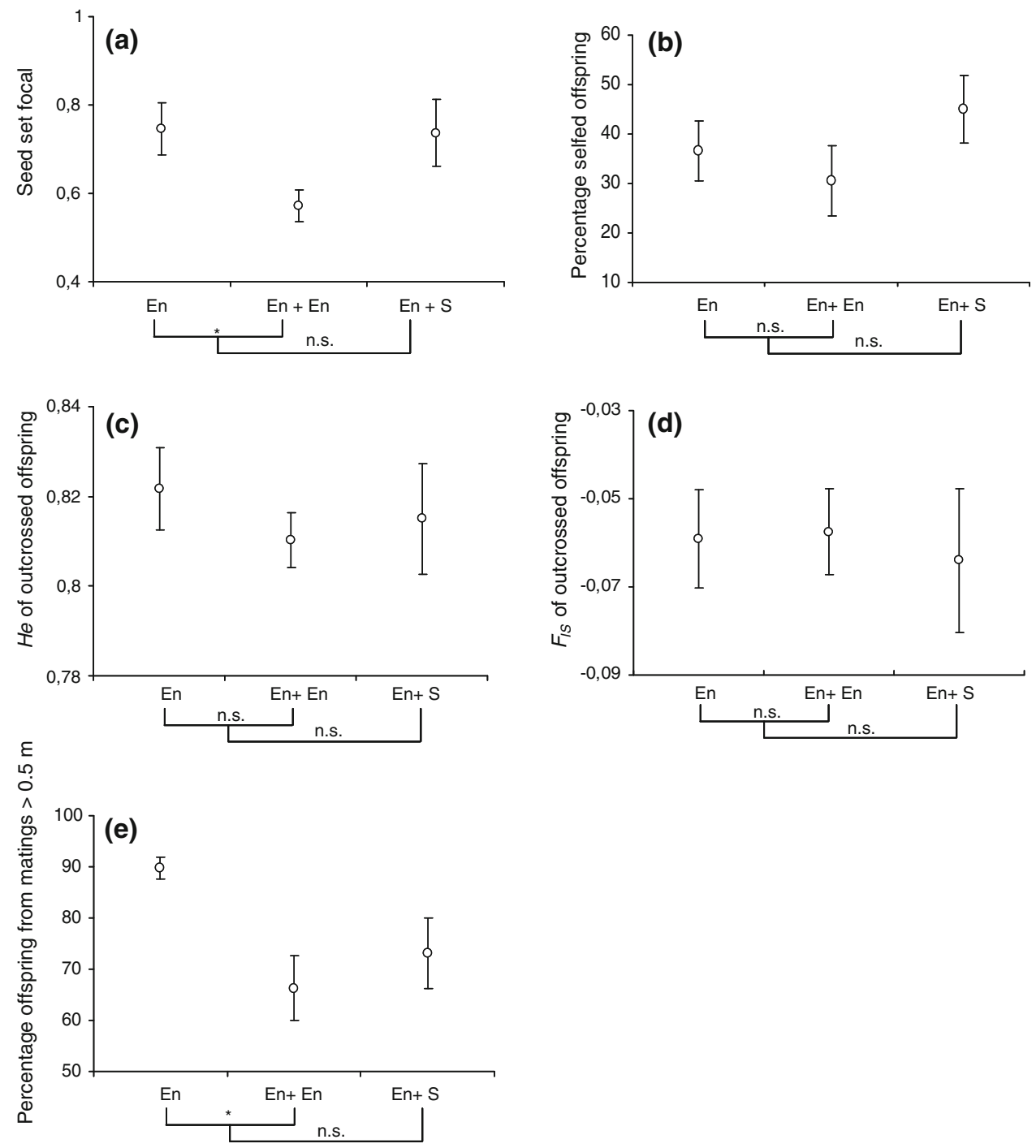

(Table 2, Fig. 2a). Study site had no effect on seed set (Table 2).

Effects of floral neighborhood on the genetic quality of offspring

A total of 524 adult E. nanum cushions and 572 embryos were genotyped and 209 distinct microsatellite alleles detected. Thirty-nine percent of all offspring resulted from self-fertilization, with outcrossing accounting for the remaining $61 \%$ of offspring. Across treatments, $33 \%$ of the outcrossed offspring were sired by a father within the plots, while $67 \%$ were sired by fathers outside the plots. Of the outcrossed offspring sired by fathers within the study plots, $63 \%$ were sired by fathers from within the inner circle (close matings at distances $<0.5 \mathrm{~m}$ ) and $37 \%$ were sired by fathers from within the $1.5-\mathrm{m}$ ring of each plot (intermediate matings $<1.5 \mathrm{~m}$ ).
Treatment had no detectable effect on the percentage of selfed offspring or on the heterozygosity $\left(H_{\mathrm{e}}\right)$ or fixation indices $\left(F_{\text {IS }}\right)$ of outcrossed E. nanum offspring (Table 2, Fig. 2b-d). However, there was an effect on the degree of outbreeding among the outcrossed offspring. Although the percentage of offspring derived from close matings $(<0.5 \mathrm{~m})$ versus intermediate plus distant matings $(>0.5 \mathrm{~m})$ did not vary significantly across the three floral neighborhood treatments tested together $(P=0.089$, Table 2$)$, the orthogonal contrast between treatments En and En + En revealed a significant difference, with the latter treatment only producing about $75 \%$ as many seed sired by intermediate and distant matings than treatment En (Table 2, Fig. 2e). These matings should confer a higher probability that the offspring carry alleles across loci that are unshared with the maternal parent. Indeed, the percentage of unshared alleles was higher in offspring of intermediate or distant matings than in those from close matings 


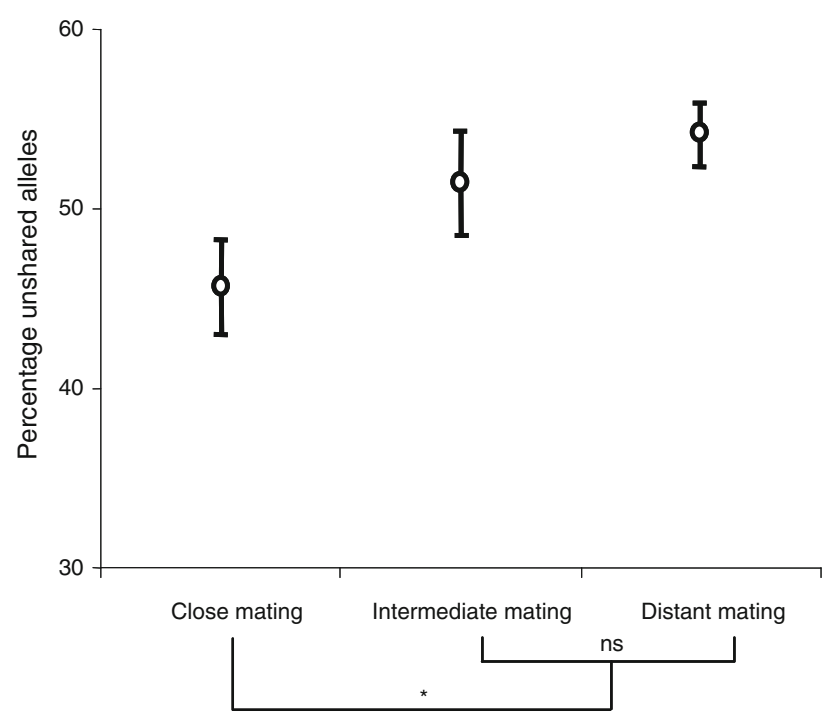

Fig. 3 Mean percentage $( \pm$ SE) of unshared alleles in outcrossed $E$. nanum offspring for three classes of matings described in the text. For the contrasts shown below the $x$-axis, the asterisk indicates means that are significantly different $(P<0.05)$; $n s$ not significant

$(P=0.016$; Fig. 3). Compared to the higher density En + En treatment, therefore, the En treatment yielded both a higher proportion of offspring from more distant sires and a greater degree of outbreeding in those offspring.

\section{Discussion}

Effects of floral neighborhood on seed set

From the experiment described here we conclude that the presence of Saxifraga spp. in the immediate floral neighborhood had neither a facilitative nor a competitive effect on E. nanum mediated through insect pollination, at least in terms of seed set, a measure of fecundity through the female sex function. We are aware of only two similar experimental studies from other arctic or alpine habitats. Armbruster and McGuire (1991) and McGuire and Armbruster (1991) used small arrays of potted plants to manipulate the floral neighborhoods of two pairs of native species in Alaska and detected no interspecific effects on seed set. The interplant spacing used in these two studies was $0.5 \mathrm{~m}$, which resembles our spatial scale, and their result of neutrality agrees with our result.

In contrast, more numerous experiments performed at lower elevations and latitudes have reported reproductive effects of plant associations that range from interspecific competition to neutrality to facilitation (e.g., Waser 1983; Laverty 1992; Moeller 2004; Ghazoul 2006; Sargent and Ackerly 2008; Mitchell et al. 2009). This greater range of outcomes may derive from a greater variety among studies in terms of properties of the flowers (e.g., of type of rewards, floral architecture, and morphology of sex parts), of the pollinators (e.g., taxon identity, sensory and cognitive abilities, and flight ranges), and of the climatic and landscape context (which might influence how pollinators move about and their choices of flowers). It also might reflect a greater variety of spatial scales used in the previous experiments. In general, any given effect of plant association-whether competition, neutrality, or facilitation-might be detectable at one spatial scale but not necessarily at a larger or smaller scale (Geber and Moeller 2006).

A recognition of spatial scale certainly also applies to our own results. Although we detected no facilitation of E. nanum by neighboring Saxifraga, for example, the overall presence of Saxifraga in an area might still facilitate $E$. nanum by attracting or supporting additional pollinator species or individuals. The support of additional pollinators might furthermore have a temporal dimension (Waser and Real 1979) in addition to a spatial one. Currently, there are too few published studies to enable any generalized statements on how interactions among plant species that attract some of the same pollinators might depend on spatial scale (and none of the studies that we are aware of have considered temporal scale in the sense of Waser and Real 1979). We thus caution against any premature attempt to estimate the overall relative prevalence of facilitation, neutrality, or competition among plants as mediated through pollination.

In contrast to the lack of detectable interspecific effects, the fecundity of E. nanum did respond to conspecific density. Whereas many studies have reported higher seed or fruit set at higher conspecific densities (e.g., Sih and Baltus 1987; Feinsinger et al. 1991; Kunin 1993; Roll et al. 1997; Bosch and Waser 2001; Feldman 2006, 2008; ZornArnold and Howe 2007), and others have detected no effect of density (Caruso 1999; Moeller 2004), we found that seed set of E. nanum was higher at lower conspecific density. Working with a biennial gentian, Spigler and Chang (2008) similarly reported a decline in fruit set with increasing conspecific density at spacings of $<1 \mathrm{~m}$. Intriguingly, they saw the opposite result with spacings of 1-4 m. These researchers suggested that negative density effects among near neighbors might arise from resource competition. Conceivably, resource competition, rather than intraspecific competition for pollination services, might also explain our result, since our plants grew in situ and could have interacted via shared resources other than pollinators. On the other hand, if this form of resource competition was occurring, it might also have been expected between neighboring Saxifraga and E. nanum. Conspecific density effects that are unambiguously mediated through pollination certainly are possible, and these have been demonstrated in the past through manipulations of potted plants, 
which cannot interact via resource competition (e.g., Bosch and Waser 2001).

Effects of floral neighborhood on the genetic quality of offspring

The genotyping of offspring allowed us to investigate additional influences of floral neighborhood. Once again, the presence of Saxifraga had no detectable effect on the proportion of selfed E. nanum offspring or the expected heterozygosity and fixation indices of outcrossed nutlets. On the other hand, the number of matings with distant sires as well as degree of outbreeding of outcrossed offspring increased significantly at low compared to high conspecific density. A growing body of literature suggests that viability and fecundity are sensitive to the degree of outbreeding, i.e., the continuum of genetic dissimilarity between parents (Waser and Williams 2001; Leimu et al. 2006). The effects of greater outbreeding on offspring viability are often positive (Teixeira et al. 2009), in which case E. nanum may benefit from low conspecific density by this effect as well as by higher seed set. It also must be noted that effects of greater outbreeding beyond some point can be negative (i.e., outbreeding depression; Waser 1993; Waser et al. 2000). The final test of such fitness effects is to grow offspring under similar, preferably natural conditions, but this experimental design is often impractical, as it was here for E. nanum, due to low seed germination $(<3 \%$, L. Wirth, unpublished). However, it is possible that the higher seed set of E. nanum at lower conspecific density is itself an effect, at least in part, of greater outbreeding of the nutlets, which increases their viability or the degree to which they are provisioned by the maternal parent as they are maturing (Waser 1993; Bernasconi et al. 2004).

\section{Possible mechanisms of conspecific density effects} in E. nanum

No interspecific interaction between Saxifraga spp. and E. nanum was detected in our high-elevation sites-neither the facilitation that we thought might occur because of a combined floral display nor competition, which also was possible. We recognize that this result applies only to the spatial scale we studied and that it underscores how much there still is to learn about the responses of insect pollinators (in particular, the dipterans that are the main pollinators of E. nanum and Saxifraga; Zoller et al. 2002) to visual and olfactory floral cues (Raguso 2004; Chittka and Raine 2006). Indeed, the same can be said about how pollinator behavior might have led to the observed effects of lower conspecific density on seed set and on genotypic makeup of seed offspring in E. nanum. The higher seed set at low density suggests reduced competition for pollinator visits at low density. The higher average degree of outbreeding of outcrossed nutlets at low density in turn corresponded to the fact that a greater fraction of these offspring had fathers from outside the plots. The causal interpretation is that kinship declines with physical distance (Heywood 1991; Glaettli et al. 2006; Williams 2007) so that longer distance pollinations yield more outbred seeds. Alpine dipterans do have the potential to fly across the considerable distances that often separate patches of alpine vegetation (Schröter 1926). However, not all flowerto-flower flights will be long, especially once a pollinator has entered a patch (Waser 1982). That a smaller percentage of seeds was fathered from beyond the immediate floral neighborhood at higher densities, either of $E$. nanum alone or mixed with Saxifraga, could suggest that more pollinator flights in dense patches were between neighbors, which in turn tend to be related.

Acknowledgments The experiments described here were carried out in compliance with the current law of Switzerland. Corresponding permits were issued by the Canton of Grisons and the local communities of Avers, Pontresina, and Silvaplana. For discussion, assistance, and comments on the manuscript, we thank Yasemin Sieber, Kirsti Määttänen, Urs Kamm, Nike Kräutler, Reto Buser, Simon Weber, Sabine Brodbeck, Michèle Büttner, Pia Slamanig, Andy Schürch, Mary Price, Hansruedi Wirth, and two anonymous referees. Several mountain cable car companies kindly provided free transport. The Genetic Diversity Center at ETH Zürich provided technical assistance. This study was supported by the Swiss National Science Foundation (3100A0-107962) and was associated to the CCES BioChange project of the ETH domain.

\section{References}

Antonovics J, Ellstrand NC (1984) Experimental studies on the evolutionary significance of sexual reproduction. I. A test of the frequency dependent selection hypothesis. Evolution 38:103-115

Armbruster WS, McGuire AD (1991) Experimental assessment of reproductive interactions between sympatric Aster and Erigeron (Asteraceae) in interior Alaska. Am J Bot 78:1449-1457

Arroyo MTK, Primack R, Armesto J (1982) Community studies in pollination ecology in the high temperate Andes of central Chile. I. Pollination mechanisms and altitudinal variation. Am J Bot 69:82-97

Bell JM, Karron JD, Mitchell RJ (2005) Interspecific competition for pollination lowers seed production and outcrossing in Mimulus ringens. Ecology 86:762-771

Bernasconi G, Ashman T-L, Birkhead TR, Bishop JDD, Grossniklaus U, Kubli E, Marshall DL, Schmid B, Skogsmyr L, Snook RR, Taylor D, Till-Botraud L, Ward PI, Zeh DW, Hellriegel B (2004) Evolutionary ecology of the prezygotic stage. Science 303:971-975

Bosch M, Waser NM (1999) Effects of local density on pollination and reproduction in Delphinium nuttallianum and Aconitum columbianum (Ranunculaceae). Am J Bot 86:871-879

Bosch M, Waser NM (2001) Experimental manipulation of plant density and its effect on pollination and reproduction of two confamilial montane herbs. Oecologia 126:76-83

Callaway RM, Brooker RW, Choler P, Kikvidze Z, Lortie CJ, Michalet R, Paolini L, Pugnaire FI, Newingham B, Aschehoug 
ET, Armas C, Kikodze D, Cook BJ (2002) Positive interactions among alpine plants increase with stress. Nature 417:844-848

Campbell DR (1985) Pollen and gene dispersal: the influence of competition for pollination. Evolution 39:418-431

Caruso CM (1999) Pollination of Ipomopsis aggregata (Polemoniaceae): effects of intra- vs. interspecific competition. Am J Bot 86:663-668

Chase MR, Moller C, Kesseli R, Bawa KS (1996) Distant gene flow in tropical trees. Nature 383:389-399

Chittka L, Raine NE (2006) Recognition of flowers by pollinators. Curr Opin Plant Biol 9:428-435

Choler P, Michalet R, Callaway RM (2001) Facilitation and competition on gradients in alpine plant communities. Ecology 82:3295-3308

Feinsinger P, Tiebout HM, Young BE (1991) Do tropical birdpollinated plants exhibit density-dependent interactions? Field experiments. Ecology 72:1953-1963

Feldman TS (2006) Pollinator aggregative and functional responses to flower density: does pollinator response to patches of plants accelerate at low-densities? Oikos 115:128-140

Feldman TS (2008) The plot thickens: does low density affect visitation and reproductive success in a perennial herb and are these effects altered in the presence of a co-flowering species? Oecologia 156:807-817

Gams H (1975) Boraginaceae. In: Berger H (ed) Gustav Hegi, Illustrierte Flora von Mitteleuropa V(1). Parey, Berlin, pp 2122-2233

Geber MA, Moeller DA (2006) Pollinator responses to plant communities and implications for reproductive character evolution. In: Harder LD, Barrett SCH (eds) Ecology and evolution of flowers. Oxford University Press, Oxford, pp 102-119

Ghazoul J (2006) Floral diversity and the facilitation of pollination. J Ecol 94:295-304

Glaettli M, Pescatore L, Goudet L (2006) Proximity-dependent pollen performance in Silene vulgaris. Ann Bot 98:431-437

Heywood JS (1991) Spatial analysis of genetic variation in plant populations. Annu Rev Ecol Syst 22:335-355

Kaplan K (1995) Saxifragaceae. In: Conert H, Jäger E, Kadereit J, Schultze-Motel W, Wagenitz G, Weber H (eds) Gustav Hegi, Illustrierte Flora von Mitteleuropa IV(2A). Blackwell, Berlin, pp 130-229

Kikvidze Z, Pugnaire FI, Brooker RW, Choler P, Lortie CJ, Michalet R, Callaway RM (2005) Linking patterns and processes in alpine plant communities: a global study. Ecology 86:1395-1400

Körner C (2003) Alpine plant life. Springer, Berlin

Kunin WE (1993) Sex and the single mustard population-density and pollinator behavior effects on seed set. Ecology 74:2145-2160

Laverty TM (1992) Plant interactions for pollinator visits-a test of the magnet species effect. Oecologia 89:502-508

Leimu R, Mutikainen P, Koricheva J, Fischer M (2006) How general are positive relationships between plant population size, fitness and genetic variation? J Ecol 94:942-952

McGuire AD, Armbruster WS (1991) An experimental test for reproductive interactions between two sequentially blooming Saxifraga species (Saxifragaceae). Am J Bot 78:214-219

Mitchell RJ, Flanagan RJ, Brown BJ, Waser NM, Karron JD (2009) New frontiers in competition for pollination. Ann Bot 103:1403-1413

Moeller DA (2004) Facilitative interactions among plants via shared pollinators. Ecology 85:3289-3301

Morales CL, Traveset A (2008) Interspecific pollen transfer: magnitude, prevalence and consequences for plant fitness. Crit Rev Plant Sci 27:221-238

Price MV, Waser NM (1979) Pollen dispersal and optimal outcrossing in Delphinium nelsoni. Nature 277:294-297
Raguso RA (2004) Flowers as sensory billboards: progress towards an integrated understanding of floral advertisement. Curr Opin Plant Biol 7:434-440

Rathcke B (1983) Competition and facilitation among plants for pollination. In: Real LA (ed) Pollination biology. Academic Press, Orlando, pp 305-329

Roll J, Mitchell RJ, Cabin RJ, Marshall DL (1997) Reproductive success increases with local density of conspecifics in a desert mustard (Lesquerella fendleri). Conserv Biol 11:738-746

Sargent RD, Ackerly DD (2008) Plant-pollinator interactions and the assembly of plant communities. Trends Ecol Evol 23:123-130

Schmitt J, Gamble SE (1990) The effect of distance from the parental site on offspring performance in Impatiens capensis: a test of the local adaptation hypothesis. Evolution 44:2022-2030

Schröter C (1926) Das Pflanzenleben der Alpen. Raustein, Zürich

Sih A, Baltus MS (1987) Patch size, pollinator behavior, and pollinator limitation in catnip. Ecology 68:1679-1690

Sork VL, Nason J, Campbell DR, Fernandez JF (1999) Landscape approaches to historical and contemporary gene flow in plants. Trends Ecol Evol 14:219-224

Spigler RB, Chang SM (2008) Effects of plant abundance on reproductive success in the biennial Sabatia angularis (Gentianaceae): spatial scale matters. J Ecol 96:323-333

Teixeira S, Foerster K, Bernasconi G (2009) Evidences for inbreeding depression and post-pollination selection against inbreeding in the dioecious plant Silene latifolia. Heredity 102:101-112

Thrall PH, Young A (2000) AUTOTET: a program for analysis of autotetraploid genotypic data. J Hered 91:348-349

Waser NM (1982) A comparison of distances flown by different visitors to flowers of the same species. Oecologia 55:251-257

Waser NM (1983) Competition for pollination and floral character differences among sympatric plant species: a review of evidence. In: Jones CE, Little RJ (eds) Handbook of experimental pollination biology. Van Nostrand Reinhold, New York, pp 277-293

Waser NM (1993) Population structure, optimal outbreeding, and assortative mating in angiosperms. In: Thornhill NW (ed) The natural history of inbreeding and outbreeding. Theoretical and empirical perspectives. University of Chicago Press, Chicago, pp 173-199

Waser NM, Real LA (1979) Effective mutualism between sequentially flowering plant species. Nature 281:670-672

Waser NM, Williams CF (2001) Inbreeding and outbreeding. In: Fox C, Roff D, Fairbairn D (eds) Evolutionary ecology: concepts and case studies. Oxford University Press, Oxford, pp 84-96

Waser NM, Price MV, Shaw RG (2000) Outbreeding depression varies among cohorts of Ipomosis aggregata planted in nature. Evolution 54:485-491

Williams CF (2007) Effects of floral display size and biparental inbreeding on outcrossing rates in Delphinium barbeyi (Ranunculaceae). Am J Bot 94:1696-1705

Wirth LR, Graf R, Gugerli F, Landergott U, Holderegger R (2010a) Lower selfing rate at higher altitudes in the alpine plant Eritrichium nanum (Boraginaceae). Am J Bot 97:899-901

Wirth LR, Graf R, Gugerli F, Landergott U, Holderegger R (2010b) Between-year variation in seed weights across altitudes in the high-alpine plant Eritrichium nanum. Plant Ecol 207:227-231

Wirth LR, Graf R, Brodbeck S, Reber-Funk C, Holderegger R, Landergott U (2009) Fully informative microsatellite markers for the tetraploid plant Eritrichium nanum (Boraginaceae). Mol Ecol Res 9:312-314

Zoller H, Lenzin H, Erhardt A (2002) Pollination and breeding system of Eritrichium nanum (Boraginaceae). Plant Syst Evol 233:1-14

Zorn-Arnold B, Howe HF (2007) Density and seed set in a selfcompatible forb, Penstemon digitalis (Plantaginaceae), with multiple pollinators. Am J Bot 94:1594-1602 